\title{
NSU - 30 VUOTTA KRIITTISTÄ YHTEISPOHJOISMAISTA TUTKIMUSTA
}

NSU:n (Nordisk Sommeruniversitet) - jonka suomenkieliseksi nimeksi on vakiintunut "Pohjoismainen kesäakatemia" - XXX. kesäkokous pidettiin elokuussa Suomessa, Kiljavan ay-opiston tiloissa. Luonteelleen uskollisena NSU ei erityisemmin juhlinut 30vuotispäiväänsä, vaan vietti sitä rutiininomaisesti työn merkeissä. NSU:n toiminta poikkeaakin ylipäänsä perinteisestä yliopistosta. Itse NSU:n nimi, "Pohjoismainen kesäakatemia"' on hieman harhaanjohtava. Pohjoismainen järjestö NSU kyllä on, mutta ei mikään "kesäakatemia"' suomalaisten kesäyliopistojen mielessä. NSU:n vuosittainen huipentuma, kesäkokous, on vain jäävuoren huippu sen toiminnassa. Siltä puuttuvat myös kaikki yliopistolaitoksen tunnusmerkit - sekä muodollisessa että sisällöllisessä merkityksessä. Parhaiten sitä voisi ehkä luonnehtia kriittiseksi 'platoniseksi akatemiaksi', joka ilman mahtipontisia ulkoisia muotoja pyrkii kriittisen järjen viljelemiseen.

\section{Mitä NSU on?}

NSU on avoinna kaikille jotka haluavat tehdä kriittistä intellektuaalista työtä. Sääntöjen mukaan NSU:n tarkoituksena on "edistää kriittistä tietämystä tieteen perusongelmista, tieteenvälisistä kysymyksenasetteluista, eri tieteiden metodisesta omalaatuisuudesta ja asemasta yhteiskunnassa"'.

Työskentely NSU:ssa jakautuu kahteen osaan. Ympäri vuoden työskennellään opintoryhmissä, ns. kretseissä, kaikkien Pohjoismaiden korkeakoulupaikkakunnilla. Yksi kretsi toimii keskimäärin kolme vuotta. Kukin opintoryhmä työskentelee yhden noin kahdestatoista kulloinkin NSU:n ohjelmassa olevan kretsiaiheen pohjalla. Toisaalta vuosittain kokoonnutaan kesäkokoukseen, joka järjestetään joka vuosi eri Pohjoismaassa. Siellä tapaa pari sataa kretsien osanottajaa toisensa tehdäkseen yhteenvetoa työstään lähes kahden viikon ajan.
Kulloinkin toimivien opintoryhmien lukumäärä vaihtelee NSU:ssa 150:n ja 180:n välillä. Tällä hetkellä kretsien työskentelyyn osallistuu aktiivisesti yli 1500 henkilöä kaikista Pohjoismaista.

NSU:n hallituksen hiljattain tekemän selvityksen mukaan NSU:n toimintaan aktiivisesti osallistuvista noin puolet oli suorittanut akateemisen loppututkinnon ja näistä yhdellä neljäsosalla oli korkeampi kuin kandidaattitutkinto. Kaksi viidesosaa on opiskelijoita, joista useimmat ovat opintojensa loppuvaiheessa. Valtaosa NSU:laisista toimii siis yliopistojen piirissä, ja he ovat pääasiassa nuorempia tutkijoita, opettajia ja opiskelijoita.

Mutta NSU:n toimintaa ei voi ymmärtää pelkkien lukujen valossa. Tämä johtuu ennen muuta NSU:n ei-etabloituneesta luonteesta, sen virallisesta epämuodollisuudesta, osanottajien vapaaehtoisuudesta ja omakohtaisesta innostuneisuudesta. Missään akateemisessa turhantärkeyden, meriittikilpailun ja autoritaarisesti pönkitetyn arvovallan ilmapiirissä tuskin voisi tavata sellaista jatkuvaa intensiivistä uusien tieteenalojen ja -perspektiivien kehittelyä, fakkirajojen ylittämistä sekä eri tieteenalojen, miljöiden ja traditioiden yhteistyötä kuin NSU:ssa.

Byrokratia on NSU:ssa minimoitu parin hengen sihteeristöksi. Hallituksen valitsee edustajisto kesäkokouksessa, jonka aikana pidetään myös yleiskokous. Eri Pohjoismaissa toimivat lisäksi paikallisosastot, jotka organisoivat oman maan toimintaa. Käytännöllisesti katsoen lähes kaikki luottamustehtävät ovat palkattomia.

Kuten sanottu, NSU:n toiminnan ytimen muodostavat edellä mainitut ns. kretsit. Tällä haavaa kretsejä on kaksitoista: (1) Evoluutioteorian tieteellinen ulottuvuus, (2) Vaihtoehdot kaupalliselle musiikille, (3) Sosialisaatiotutkimus ja instituutioanalyysi, (4) Työntekijäja aikuiskasvatus Pohjolassa, (5) Keskikerrostumien yhteiskunnallinen funktio, organisoituminen ja tietoisuus, (6) Urheilu yhteiskun- nallisessa perspektiivissä, (7) Naisliike ja naistutkimus, (8) Systeemiajattelun teoria ja käytäntö yhteiskunnallisessa perspektiivissä, (9) Paikallishistoria, (10) Elämäntapa, terveys ja sairaus, (11) Maailmantalous ja kansallisvaltio muutoksessa, (12) Sosiaaliset utopiat konkreettiset utopiat tänään. Näistä kuusi $(2,3,8,9,10,11)$ on tullut ohjelmaan tämän kesän kesäkokouksessa.

Opintotoiminnan ohessa NSU:n toinen merkittävä toimintamuoto ovat julkaisut. Vuosina 1952-59 julkaistiin vuosikirjaa, jota ehti ilmestyä kuusi volyymia, ja vuosina 1959-63 englanninkielistä sarjaa "Interdisciplinary Studies from the Scandinavian University", yhteensä toistakymmentä julkaisua. Vuodesta 1966 NSU on julkaissut yhteispohjoismaista tutkimus- ja korkeakoulupoliittista aikakauslehteä Nordisk Forum, joka ilmestyy neljä kertaa vuodessa. Nykyisin Nordisk Forumilla on tapana julkaista erityisiä teemanumeroita, joiden aihepiiri ammennetaan tavallisesti kretsien toiminnasta.

- NSU:n kirjasarjassa, joka on nyt päätetty lopettaa, on ilmestynyt kymmenkunta teosta, viimeisenä tänä vuonna ilmestyvä antologia "Historie, vitenskap og samfunn". Tästedes tyydytään painoasultaan vaatimattomampaan julkaisuun "Arbejdspapirer fra NSU', joka perustettiin viime vuonna.

\section{NSU: $n$ historia}

NSU perustettiin pohjoismaisen yliopistoväen toimesta kokouksessa, joka pidettiin Lysebussa Oslon ulkopuolella 12.-16. elokuuta 1950. Siellä laadittiin ensimmäinen opinto-ohjelma, ja vajaan vuoden kuluttua järjestettiin ensimmäinen kesäkokous Askovissa Tanskassa.

Jos joku ansaitsee arvon "NSU:n perustaja", niin se kuuluu Kööpenhaminan yliopiston silloiselle tanskan kielen professorille Poul Diderichsenille. Diderichsen kertoo itse NSU:n ensimmäisessä 
vuosikirjassa (1952) että perustamisaloite tuli tanskalaisten professorien ja opiskelijoiden taholta. Esikuvana oli "Internationale Hochschulwochen", joka oli luotu Itävallassa 1945. Pohjoismaisten opettajien ja opiskelijoiden vapaan yhteenliittymän perustamisella oli kaksi päätavoitetta: ensinnäkin NSU:n suuri johtoajatus tieteidenvälisestä tutkimuksesta ja toiseksi pohjoismaisen yhteistyön elävöittäminen.

Tieteidenvälisyyden painotus tuli esiin jo tavoiteparagraafissa, jossa todettiin että "jokaisen opintopiirin tuli käsitellä ongelmia joilla on merkitystä vähintään kahdelle eri tieteenalalle". Tieteidenvälisyys on ollut - kriittisen hengen ohessa - NSU:n toiminnan perustunnus. Tieteidenvälinen ajattelu sekä yksipuolisesti fakkiutuneen erikoistumisen kritiikki ovat toimineet myős käytännössä traditionaalisen yliopistojärjestelmän kritiikkinä. Käytännöllisiä seurauksia tällä on ollut erityisesti Tanskassa, missä on 70-luvulla kehitetty tieteidenvälisiä opintoja Århusin yliopistossa sekä uusissa yliopistokeskuksissa Roskildessa ja Ålborgissa. Suomessa vaikutus ei ole ollut näin selvä, mutta luultavasti monet NSU:n toimintaan osallistuneet suomalaiset ovat osaltaan 'salakuljettaneet' tieteidenvälistä ajattelua Suomeen. 60-luvulla syntyneen kriminologisen tutkimuksen kohdalla vaikutus on ehkä selvin, mutta mainittakoon myös että esimerkiksi Suomen Akatemian nykyinen tutkimusjohtaja Elisabeth Helander osallistui aktiivisesti NSU:n toimintaan 60-luvulla.

Luonnollisesti NSU on myös muuttunut ajan kuluessa, vaikka peruslinja onkin säilynyt muuttumattomana. Muutosta voi sanoa tapahtuneen liberalistisesta selvemmin kriittis-edistykselliseen suuntaan. Samanaikaisesti osanottajien rekrytointi NSU:hun on laajentunut ja professorivaltaisuus on hävinnyt.

Tätä muutosta kuvaa myös kesäkokousten tyylin tietty muutos. Kun vuonna 1952 kesäkokous pi- dettiin Norjassa tunturihotellissa ja avajaisjuhlallisuudet hotellin tanssisalissa, niin vuonna 1976 kesäkokous oli Tanskassa Tvindkouluilla (jotka ovat tunnettuja mm. suuresta modernista tuulimyllystä), missä kaikki osanottajat osallistuivat vuorollaan myös käytännön töihin aina ruuanlaittoa ja siivousta myöten.

Itse NSU:n opintotoiminnassa 50-luvun NSU:laisten voi kuitenkin sanoa aikanaan olleen yhtä radikaaleja kuin myöhempien polvien. He käsittelivät kesäkokouksissa ajankohtaisia yhteiskunta- ja yliopistopoliittisia kysymyksenasetteluja samoin kuin klassisia filosofisia ongelmia. Osanottajina oli Pohjoismaiden huomattavimpia kulttuuripersoonallisuuksia ja intellektuelleja: Niels Bohr, Ingemar Hedenius, Herbert Tingsten, Johan Torgersen ja Anders Wedberg - unohtamatta NSU:n suomalaisia nestoreita, filosofian professoreita Sven Krohnia Turusta ja Raili Kauppia Tampereelta. Myös Mauno Koiviston kerrotaan kohentaneen ruotsinkielen taitoaan NSU: ssa 50-luvulla.

Hyvä esimerkki NSU:n tieteidenvälisestä toiminnasta 60 -luvulla ovat oikeustieteilijöiden ja sosiologien yhteisesti muodostamat kretsit. Näillä oli huomattavaa merkitystä kriminologian ja oikeussosiologian läpimurrolle Pohjoismaissa. Erityisesti norjalaiset tutkijat kuten Vilhelm Aubert, Niels Christie ja Thomas Mathiesen ovat saavuttaneet mainetta tällä alalla, mutta myös sellaisten NSU-aktiivien nimet kuin Inkeri Anttila, Risto Jaakkola, Heikki Jokela, Raimo Lahti, K.J. Lång, Klaus Mäkelä, Patrick Törnudd ja Paavo Uusitalo kertovat jotain Suomen osalta. Johan Galtung oli puolestaan tuomassa rauhantutkimusta NSU: hun.

\section{Kapinavuodet}

Vuonna 1968 Euroopassa ja USA:ssa puhjenneet opiskelijakapinat eivät vielä samana vuonna heijastuneet NSU:n kesäkokouksessa, joka pidettiin Islannissa. Mutta vuonna 1969 Trondheimissa antiautoritaarinen opiskelijaliike tavoitti myös NSU:n. NSU:n sääntöihin sisällytettiin tällöin toivomus että jäsenet "suhtautuisivat kriittisesti olemassaoleviin yhteiskuntasuhteisiin Pohjolassa ja sen ulkopuolella sekä ryhtyisivät kaikkien tieteellisten disipliinien kriittiseen arviointiin". Näin radikaali opiskelijaliike löi leimansa myös NSU:hun. NSU oli jälleen kerran eräänlainen radikaali vaihtoehto etabloituneille yliopistoille. Eikä siellä tarvinnut tuhlata aikaansa tappeluun reaktionääristen professorien kanssa.

NSU:ssa kapina kanavoitui kuitenkin tieteelliseen työskentelyyn ja opiskeluun. Vuonna 1970 aloitettiin sellaiset kretsit kuin "Mitä on kriittinen tiede?" ja "'Imperialismi". Seuraavana vuonna ohjelmaan tuli itse "Karl Marx: Das Kapital", josta tanskalainen Peter Madsen, nykyisin tunnettu kielitieteilijä, teki aloitteen.

'’Pääoma"'-kretsistä tuli suuri menestys kaikissa Pohjoismaissa. Sillä oli varsin merkittävä vaikutus marxilaisen tutkimuksen leviämiseen Pohjoismaiden yliopistoihin 70-luvulla. Sieltä ovat peräisin myös aikoinaan hyvinkin kiivaat, mutta nyt jo laantuneet kiistat tanskalaisten ns. pääomaloogikoiden ja suomalaisten valtiomonopolistisen kapitalismin teoreetikoiden välillä.

Opiskelijaliikkeen hurjimman vaiheen taituttua 1972 NSU:n uusi profiili alkoi selkiytyä. Marxilainen tutkimusote oli toki tullut jäädäkseen, mutta tuskin se koskaan oli ollut yksin dominoiva. Opiskelijaliikkeen esiinnostamat teemat yhteiskuntakriittisestä tiede- ja yliopistopolitiikasta (vrt. tunnus "'tiedettä kansalle") vakiinnuttivat asemansa NSU:n piirissä. Erityisesti tieteen, yliopiston ja yhteiskunnan väliset suhteet otettiin uudelleen pohdittaviksi. Samanaikaisesti syntyi uusia opintoryhmien aiheita. Semiotiikka oli eräs 'muotiaihe' josta keskusteltiin usein NSU:n 


\section{VALONSÄTEITÄ VANKILASTA}

julkaisuissa. Vuonna 1973 naiskysymys tuli ensimmäistä kertaa kretsin aiheeksi NSU:ssa, ja siitä lähtien, lyhyttä poissaoloaan lukuunottamatta, "naiskretsi" on ollut eräs NSU:n kaikkein vahvimpia kretsejä. Tähän on ollut syynä ennen muuta Tanskassa, Norjassa ja Ruotsissa voimakas feministinen liike. Ekologia eri muodoissaan on puolestaan ollut perinteisesti NSU:n opinto-ohjelmassa vuodesta 1952 lähtien tähän päivään saakka.

70-luvun kuluessa vasemmistolaisen opiskelijaliikkeen merkitys on vähentynyt NSU:ssa - niin kuin muutenkin Pohjoismaissa (NSU:ssa on siis tässäkin suhteessa heijastunut varsin selvästi Pohjoismaiden yleinen yhteiskunnallispoliittinen kehitys).

\section{Nykytilanne}

Avoimen kriittinen linja, joka alkoi NSU:ssa 1969, on eri Pohjoismaiden oikeistopoliitikoissa herättänyt poliittista epäluuloa, ja he ovat 70-luvulla pyrkineet rajoittamaan NSU: $n$ toimintaa taloudellista tukea supistamalla. Vuonna 1973 Pohjoismaisen ministerineuvoston komitea arvioi NSU:n toimintaa antaen siitä kuitenkin varsin myönteisen lausunnon. Mutta tämän jälkeenkin NSU on aika ajoin ollut lakkauttamisuhan alainen. Tällä hetkellä tilanne on kuitenkin jo valoisampi: NSU on yhtä hyvin taloudelliselta kuin sisällölliseltä perustaltaan sangen vakaa ja toimịva järjestö.

\section{Keijo Rahkonen}

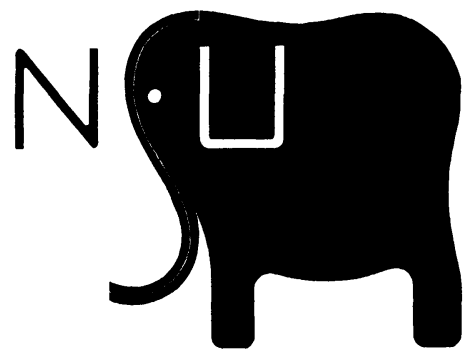

ANTONIO GRAMSCI: Vankilavihkot, valikoima. Toim. ja johdannon kirjoittanut Mikael Böök, Helsinki 1979.

Gramsci uskaltaa sanoa. Kävi siis päinvastoin kuin Gramscin vangitsijat kuvittelivat uskoessaan voivansa "estää näiden aivojen toiminnan kahdeksikymmeneksi vuodeksi". Vankila sitoi kädet mutta vapautti ajatuksen.

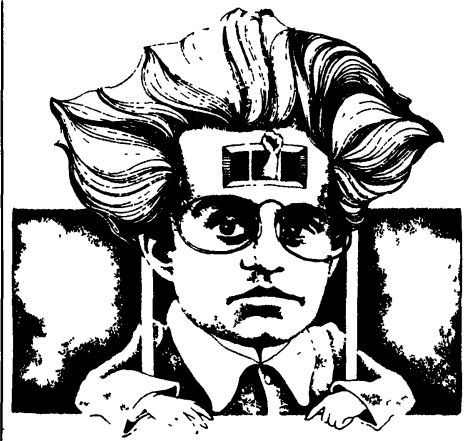

On yleinen hokema tehdä Gramscista "avoimen marxismin" edustaja, joka välttää ja varoittaa kytkemästä marxismia liian kiinteästi yhteen tai toiseen ajattelijaan. Tämä on kaksinkertaisesti liian yksinkertaista. Gramsci itse halusi huipentaa arvovallan yhteen suureen filosofiin, esikuvaan, joka voi koota kansanjoukot hegemonian valtaamiseksi. Ja Gramsci on nyt itse historiallinen henkilö. Gramsci on suuri esikuva, josta ei vain yhden kansakunnan marxilainen liike ime elinvoimaansa. Gramscin sielusta eivät taistele vain erilaiset marxilaiset. On olemassa myytti Gramscista. Siksi kannattaa lukea Gramscia ennen hänen lukemattomia apostoleitaan.

\section{Valikoiman esipuheen kuva Gramscista}

Gramscia koskeva keskustelu on Keski- ja Etelä-Euroopassa vyörynyt useassa aallossa. Suomi on neitseellinen maaperä, jonka rantoja nämä aallot eivät ole sanottavammin huuhdelleet. Voitaisiin ajatella, että on suuri houkutus tehdä suomalaiseen rantahiek- kaan ne vaot, joita pitkin keskustelu ohjautuu. Näin ei tapahtunut, koska jokaisella on nyt mahdollisuus äidinkielellä perehtyä ei vain nuoren Gramscin Ordine nuovo-vaiheen kirjoituksiin (ks. Antonio Gramsci: Työväenluokan yhtenäisyys, Moskova 1976), vaan myös valikoimaan Vankilavihkoista.

Suomentajien teknisistä ratkaisuista haluan todeta vain pari seikkaa. Vaikka tiedetään, että Gramsci kirjoitti vihkonsa silmäilyn alaisena ja sensuurin pelosta joutui muuttamaan marxilaista terminologiaa, on hyvä, että teos esitetään alaviitteitä myöten alkuperäisessä muodossa ilman mitään ohjaavia muutossääntöjä. Esipuheen huomautus riittää. Erilaisten muunnosohjeiden esittäminen saattaa helposti johtaa tulkinnan tulkintaan, koska kaikki Gramscin tekemät kielelliset muutokset eivät ole sensuurin pelkoa vaan marxilaisen ortodoksian kritiikkiä. Omaksuin helposti niin viitteiden kuin alaviitteiden joustavan käytön, jossa alkuperäistekstissä alaviitteessä ollut kohta on joskus nostettu varsinaiseen tekstiin, joskus viite on jätetty pois kokonaan. Erityisesti minua miellytti se, että kääntäjät ovat muutamassa kohdassa täydentäneet käyttämiään viitteitä suomalaisella lähteistöllä.

Gramsci-käännös on valikoima, jolle on syystä luvattu jatkoa. Valikoima käsittää yllättävän pienen osan Vankilavihkojen kokonaisuudesta, joka alkuperäismuodossaan sisältää 33 tiheärivistä vihkoa ja tuhansia sivuja. Alkuperäisen tekstin fragmentaarisuus, jopa keskeneräisyys, estää minkään yksinkertaisen kronologisen valikointikriteerin soveltamista. Suomennettu valikoima on se Vankilavihkojen osa, johon tutustuminen ehkäpä parhaiten aukaisee oven Gramscin ajatteluun. Onhan filosofis-metodologisten kysymysten pohdinta ja ratkaisut tieteellisen itseymmärryksen peruskivi. Lisäksi kääntäjien teokseen liittämä Gramscin kirje Tan- 